\title{
Produção cultural e redes de sociabilidade no currículo e no cotidiano escolar*
}

\author{
JANETE MAGALHÃES CARVALHO \\ Universidade Federal do Espírito Santo
}

Falar de produção cultural e redes de sociabilidade remete à necessária definição e/ou conceituação do que estamos entendendo por cultura(s).

Segundo Raymond Williams (2000), Herder, em 1784, teria sido o primeiro a empregar o termo cultura no plural - "culturas" - para, intencionalmente, estabelecer diferenciação com qualquer sentido singular ou unilinear de "civilização".

Para o autor, do século XVIII ao XX, houve um expressivo diferencial no sentido de cultura como cultivo ativo da mente - um estado mental desenvolvido em "pessoa de cultura", "pessoa culta" - passando por processos de desenvolvimento denominados "interesses culturais", "atividades culturais" e "produção cultural".

Desse modo, a sociologia da cultura, ao entrar na segunda metade do século $\mathrm{XX}$, apresentava uma nova forma de convergência que se expressou bem nos estudos culturais que, constituindo-se como um ramo da sociologia geral, se ocupou, fundamentalmente, da análise das práticas e das produções culturais manifestas.

Assim, a sociologia cultural se volta para os processos sociais que circunscrevem a produção cultural, tendo sido relativamente bem-sucedida quando se preocupa com formas, práticas, instituições ou períodos específicos, e relativamente malsucedida quando tenta generalizá-los como processos sociais, ou desenvolver uma teoria geral dentro da qual eles possam ser compreendidos.

Segundo Williams (idem, p. 182),

* Trabalho apresentado na 33a Reunião Anual da Associação Nacional de Pós-Graduação e Pesquisa em Educação (ANPEd), 2010, na Sessão Especial Produções culturais e redes de sociabilidade na educação (n. 08). 
[...] o que é verdade sobre "uma cultura", em seu nível mais geral - o fato de jamais ser uma forma em que as pessoas estão vivendo, num certo momento isolado, mas sim uma seleção e organização, de passado, presente, necessariamente provendo seus próprios tipos de continuidade [...].

Néstor García Canclini (2007) pontua que, na contemporaneidade, o conceito de cultura se torna difícil de estabelecer em uma sociedade que se modifica em uma velocidade nunca antes observada. Sobre essa situação de "cultura extraviada nas suas definições", Williams (2000, p. 36) observa:

[...] até há poucas décadas, pretendia-se encontrar um paradigma científico que organizasse o saber sobre a cultura, e, mesmo quem reconhecia a coexistência de múltiplos paradigmas, aspirava a estabelecer algum que fosse o mais satisfatório ou de maior capacidade explicativa.

Entretanto, a própria pluralidade de culturas contribui para a diversidade de conceituações.

Assim, buscando uma definição operacional, partimos da pressuposição da cultura como o conjunto de processos plurais de produção, circulação, uso e consumo da significação da vida social e, com Michel de Certeau (1995), consideramos sempre a "cultura no plural".

Há que se considerar, entretanto, que, mesmo entendendo cultura como o encontro e a reprodução de valores, identidades e retóricas, ou como a luta pelo significado, no sentido de que a cultura não é propriedade de ninguém, nem de grupo algum, mas um processo de negociações e de embates, os usos da cultura na era global têm-se caracterizado: a) pela adoção de políticas afirmativas em torno de interesses identitários; b) pela comunicação de massa; c) pelo consumismo. Essas questões, portanto, remetem à problematização concernente à adoção do termo indústria cultural ou cultura de massa, no contexto do capitalismo globalizado.

\section{PRODUÇÃO CULTURAL E INDÚSTRIA CULTURAL NO MUNDO GLOBALIZADO}

Segundo George Yúdice (2004), significativas transformações socioeconômicas, políticas e culturais se configuraram sob o contexto da globalização neoliberal, especialmente a partir dos anos de 1980, implicando novas interfaces entre a sociedade civil e o Estado, repercutindo também nos processos de usos e consumos da produção cultural.

$\mathrm{Na}$ América Latina, alguns fatores decorrentes do processo de globalização foram particularmente significativos: a) a nova divisão global de trabalho resultante da reestruturação econômica global; b) o desenvolvimento de mercados de capitais; c) o impacto desnacionalizador das novas tecnologias sobre as telecomunicações e a mídia; d) o surgimento do mercado global; e) o crescimento exponencial das viagens internacionais e das indústrias de turismo; f) os efeitos políticos e sociais de uma indústria expandida de artefatos culturais de todo tipo pela denominada indústria cultural. 
Sobre a atualidade do conceito de indústria cultural, Antonio Zuin (2001) argumenta que o atual desenvolvimento dos meios de comunicação de massa aumenta a sensação da inexistência de qualquer tipo de obstáculo que poderia impedir as trocas de diferentes produções e valores culturais dos mais variados países do globo. Diante, porém, de uma sociedade tecnificada, nada é mais incongruente do que a insistência na argumentação de que a massificação e o consumo da produção cultural implicam a concretização de uma sociedade mais justa e democrática.

São escamoteadores tanto os discursos voltados para uma evidente deficiência da escolarização formal quanto a causa dos problemas sociais que são vivenciados cotidianamente, como os discursos que defendem a ideia de que tais problemas seriam resolvidos pelo progressivo desenvolvimento linear de uma educação elementar para uma educação que produzisse pessoas consideradas cultas. Isso porque tais discursos desconsideram a multiplicidade dos elementos envolvidos na produção de redes de sociabilidade e subjetividade, atreladas às causas da barbárie.

Como, então, aplicar o conceito de indústria cultural? Estaríamos no reino da cultura de massa?

Antonio Negri (2005) afirma a necessidade de superação da perspectiva de indústria cultural e de cultura de massa, pois vislumbraria a produção cultural, seus usos e consumos como passivos. Debatendo os conceitos de massa e de multidão, o autor afirma a potência da segunda como singularidade que promove novas redes de sociabilidade. Nesse sentido, expõe como a singularidade e o comum anunciam elementos diversos na multidão e mudam dentro de uma dinâmica continuamente construtiva, com consequências políticas ligadas a essa relação.

Para o autor, vivemos em um tempo unificado, disperso, no qual a jornada de trabalho clássica não é medida de temporalidade, já que essa medida desapareceu ou se modificou completamente. Além disso, vivemos em uma situação na qual o espaço também se alterou completamente. $\mathrm{O}$ espaço do trabalho, da atividade, converteu-se em um espaço de inter-relações contínuas, o que supõe uma dimensão existencial e ontológica diferente, com profundas repercussões tanto na produção cultural quanto na constituição das redes de sociabilidade.

Portanto, dizemos que hoje a vida de trabalho se modificou, porque já não se trata somente de uma vida de trabalho dirigida por algum ciclo de tempo e de espaço da produção. É uma vida que é regulada, ordenada de alguma forma por uma espécie de imersão em um fluxo contínuo que Negri (idem) denomina biopolítico, porque implica efetivamente a vida, envolve formas de vida que são consequentes umas às outras, que estão ligadas umas às outras, porque o cultural, o social e o político entram como elementos absolutamente fundamentais na vida de cada pessoa em redes de sociabilidade múltiplas, atravessadas e singulares.

\section{REDES DE SINGULARIDADES E COOPERAÇÃO NA CONSTITUIÇÃO DAS REDES DE SOCIABILIDADE}

Opondo ao conceito de massa o de multidão, Negri (idem) pontua que, quando falamos de multidão, nos referimos a um conjunto, mais do que a uma soma, de 
singularidades cooperantes. Para ele, a multidão pode ser definida como o conjunto de singularidades cooperadoras que se apresentam como uma rede, uma network, um conjunto que define as singularidades em suas relações umas com as outras.

Entender a multidão como singularidades cooperantes, portanto distintas da massa passiva e amorfa, levanta o problema de sua constituição, de seu movimento em redes que se movem em singularidades e que se colocam nessa relação. A primeira característica que aparece vem definida pelo fato de que não estamos aqui diante de individualidade, e sim de singularidades. Individualidade significa algo que está inserido em uma realidade substancial, algo que tem uma consistência, independente da totalidade, em relação ao conjunto.Já a singularidade é o homem que vive na relação com o outro, que se define na relação com o outro. Sem o outro ele não existe em si mesmo.

É a partir da singularidade que se explica o comum. Buscar o comum não significa buscar realidades pressupostas, o velho conceito de comunidade profunda, o velho conceito de terra, natureza, pátria. Já são conhecidas as horríveis e perversas concepções que podem vir dessa identidade. Para Negri (idem, p. 2),

[...] em um país como o Brasil, funções, mais que conceitos, de poder e de raça se uniram profundamente para criar diferenças sociais que hoje se transformaram em hereditárias, pesadas, difíceis de superar e que supõem elementos que negam a democracia e a própria possibilidade da utopia.

Ao considerarmos que o mundo está feito de singularidades que consistem em relações e que, portanto, existem na medida em que estão em relações, aumentamos nossa capacidade de ação em redes que se convertam em reais e produtivas, nas quais a relação entre singularidade e cooperação se torna fundamental. Por exemplo, na maneira informática de conhecer, como resultado da união da paixão, da imaginação e do intelecto; maneira que cria uma nova forma de razão que não é mais a razão abstrata, mas é razão que conecta imediatamente o saber, a prática, a imaginação, o social e a cooperação. Não se trata simplesmente, nesse caso, de aprender a usar máquinas; trata-se apenas, sobretudo, de fazer passar através dessas máquinas aquela construção social que é horizontal e sempre criativa. Portanto, singularidade e cooperação se tornam fundamentais na construção de qualquer bem, mercadoria e produto.

Está claro, porém, que hoje a tentativa do capitalismo para dominar esse tipo de realidade passa pela financeirização internacional dos processos produtivos e pelas grandes forças globais de controle. É evidente que a chave está no próprio sistema. Contudo também é evidente que, dentro desse tipo de controle, há algo que falta: a capacidade de amarrar a potência do processo de singularização, do processo de invenção. Quando se fala de singularização, de invenção, fala-se também, de maneira necessária e evidente, de resistência.

A propriedade privada e a propriedade pública confrontam-se com as novas formas de propriedade flutuante em torno da rede em nível internacional e com a capacidade que as grandes empresas têm de criar seu mercado e de intervir nessa ordem mercantil e jurídica que elas criaram com a força e a capacidade de garanti-la por meio das multas, das penalidades, da exclusão etc. 
Então o que é a propriedade comum? A propriedade comum, do ponto de vista jurídico, é uma propriedade pública que, em lugar de ter patrões públicos ou donos públicos, é de sujeitos ativos naquele setor ou naquela realidade e é administrada por eles. A propriedade comum é esse ato, é essa atividade por meio da qual os sujeitos administram ou gerem, por exemplo, a rede de coletivos escolares (os Conselhos de Escola deveriam/ poderiam ter essa função?), porque a rede de educação é deles, porque o comum se tornou ou é reconhecido como uma condição para a vida, uma condição biopolítica.

Assim, a propriedade comum não passa simplesmente pelo Estado. Passa pelo exercício que as singularidades fazem desse espaço comum, pela maneira de exercer esse espaço comum. Portanto, para além da propriedade pública, a definição jurídica do comum é aquela que possibilita fazer atuar dentro do caráter público a construção de espaços comuns reais, e fazer atuar nesses espaços de vontade a decisão, o desejo e a capacidade de transformação das singularidades.

Sem respostas prontas, concluímos esta parte tentando demonstrar a urgência de movimentos singulares e cooperativos em direção à constituição do comum, procurando superar o processo de individualização das referências, inserido em agenciamentos coletivos de enunciação, envolvendo-nos tanto no cuidado de si quanto no cuidado do outro (Foucault, 2006), em busca dos movimentos de singularização e potenciação do coletivo, na escola e para além dela, visto que, segundo Michael Hardt e Antonio Negri (2005, p. 376),

[...] nenhuma subjetividade está do lado de fora, e todos os lugares foram agrupados num não lugar geral [...]. Quando dizemos que a teoria política precisa tratar da ontologia, queremos dizer em primeiro lugar que a política não pode ser construída de fora para dentro. Política é campo de pura imanência.

Desse modo, entende-se por virtual o conjunto de poderes para agir (ser, amar, transformar, criar) que reside na constituição de redes na multidão. Considerando que o conjunto virtual de poderes da multidão é construído por lutas e consolidado em desejo, torna-se necessário investigar como o virtual pode exercer pressão nas bordas do possível e, assim, produzir o comum. Segundo Hardt e Negri (idem, p. 379), "A passagem do virtual através do possível para o real é o ato fundamental de criação. $\mathrm{O}$ trabalho ativo, que constrói a passagem do virtual para o real, é o veículo da possibilidade".

Nessa perspectiva, é de grande importância a noção de trabalho imaterial como uma forma de trabalho que cria produtos imateriais, tais como: saber, informação, comunicação, relações ou, ainda, reações emocionais (Negri, 2003).

Atualmente, o trabalho é, de imediato, uma força social animada pelos poderes do conhecimento, do afeto, da informação e da linguagem na formação de redes singulares e cooperativas de todo tipo.

Em outras palavras, a resistência está imediatamente ligada ao investimento constitutivo no reino biopolítico e à formação de aparatos cooperativos de produção e de sociabilidade, entre os quais o afeto (Hardt; Negri, 2005).

Mas o que vem a ser uma rede de sociabilidade singular e cooperativa na produção do cotidiano escolar? 


\section{REDES DE SOCIABILIDADE NA PRODUÇÃO DO COTIDIANO ESCOLAR}

Buscar delinear o mapa cartográfico de uma escola oferece-nos inúmeras possibilidades de reflexão sobre seu processo de sociabilidade, sobre o seu patrimônio cultural, escolhas, discursos identitários, aspirações, táticas e estratégias em sua relação com os conflitos e afetos vivenciados em seu entorno. A escola expressa uma história coletiva anunciada nas medidas do espaço que se reflete na sua geografia e que possibilita, ainda, considerar a articulação do espaço escolar como análogo às estruturas das redes sociais. Compostas por nós (pessoas), elos (relações) e por princípios organizadores, as redes são dinâmicas e complexas, formadas por pessoas e grupos que compartilham valores ou objetivos em comum, e são interligadas de forma horizontal e predominantemente descentralizadas (Duarte et al., 2008).

Inter-relacionando os conceitos de cotidiano escolar e de redes sociais, compreende-se que as forças que geram o movimento estão entrelaçadas na teia da diferença social, histórica, econômica e cultural dos vários elos que a regem e da necessidade de troca de informações entre os diferentes tipos de nós. Visualiza-se a escola, portanto, como obra coletiva, como espaço de conquistas sociais e de acesso institucional à cidadania.

Desse modo, concebe-se o cotidiano escolar como atravessado, entrelaçado por múltiplos outros contextos cotidianos. Segundo Certeau (1995), a escola depende de uma mediação entre as relações da ordem próxima e da distante para propulsionar seu crescimento. A ordem próxima compõe as relações mais imediatas, as vinculações diretas entre as pessoas e os grupos mais ou menos organizados e desses grupos entre si, enquanto a ordem distante é regida por instituições poderosas, por um código jurídico formalizado ou não, por conjuntos significantes, concebidos no interior das formações discursivas e das instituições.

Nessa direção, deve-se buscar cartografar como essa rede contém, em sua dinâmica de formação e de incremento e em suas práticas discursivas de produção e de relacionamento, as marcas das significações com outras e múltiplas redes de sociabilidade. Ou seja, o entrelaçamento de múltiplos cotidianos, de um cotidiano das relações afetivas e familiares atado às redes de sociabilidade de vários portes: comerciais, políticos, educacionais, religiosos, de lazer etc., envolvendo as relações socioeconômicas, culturais e institucionais.

O poder cultural não está localizado em uma escola. Ele infiltra-se em qualquer teto e em qualquer espaço, por exemplo, pelas telas das televisões. Ele "personaliza-se". Hoje, a informação unitária vem pelo canal múltiplo da televisão, da publicidade, do comércio, dos cartazes etc. $\mathrm{E}$ a escola pode formar um núcleo crítico dessa informação vinda de outros lugares. Como foi frisado, a escola envolve uma pluralidade de culturas, isto é, de sistemas de referência e de significados heterogêneos entre si.

Para Certeau (1995), a cidade contemporânea torna-se um labirinto de imagens, e, por consequência, podemos inferir que a escola também. Ela se dá uma grafia própria, diurna e noturna, que dispõe de um vocabulário de imagens sobre um novo espaço de escritura. Nossas histórias estão engendradas nesse labirinto de imagens, de sonhos, de possibilidades. Assim, na produção do currículo no cotidiano escolar, estamos imbricados com o mundo, com as pessoas, com o que nos acontece. 
Fazemos colagens ("bricolagem"), construções e reconstruções... Não necessariamente nessa ordem.

$\mathrm{Na}$ escola, como na cidade, o plano do cotidiano se inscreve nas relações e nas práticas sociais que englobam a produção e a reprodução material e discursiva, os lugares específicos e os conjuntos espaciais próprios a cada formação social. Nesse processo, há de se observar que uma coletividade se organiza a partir da conexão do sentido de comunidade, a criar vínculos de proximidade. Nos bairros em que se localizam as escolas, nos agrupamentos em que se define a base da proximidade, apresentam-se os diversos padrões dos modos de constituição da comunidade local, na qual a intensificação das existências coletivas depende da diversidade das condições relacionadas com a vida do lugar, as quais, por sua vez, se interligam a movimentos sociopolítico-culturais mais amplos.

Assim, as ordens que a cidade transmite, na forma de significações, das simultaneidades e dos encontros, também atravessam a escola em suas redes de sociabilidade, obrigando os seus habitantes a reinventar suas tradições e a desvelar a realidade edificada, mantendo-a como espaço de troca e de materialização da vida humana. Nesse processo de reconstrução em outras bases sociais, culturais, afetivas etc., os habitantes dos espaços e tempos escolares esquadrinharam, na experiência da economia do saber, a refundação de sua trajetória.

Imersa nas redes e com as redes, como elos de uma corrente da teia contínua de qualquer partícula de informação, a tessitura informal é mais flexível e a informação que encerra pode se apresentar tanto em nível horizontal quanto em vertical. De acordo com Fábio Duarte et al. (2008), nessa contextura se entrecruzam incomparáveis números de discursos produzindo uma dinâmica, em nível diacrônico e sincrônico, na qual novas alocuções nascem ajudando a alterar os significados dos outros. Os discursos são compreendidos com base tanto no que está estabelecido quanto nas características referidas no universo dos partícipes desse processo.

O mapa cartográfico apresenta o coletivo tecido em rede - decorrência não somente do código de reciprocidade, mas também da troca de informação e cooperação, deslocando-se nas várias dimensões das atividades de uso, consumo e produção de conhecimentos, linguagens e afetos.

\section{OS USOS E CONSUMOS DA PRODUÇÃO CULTURAL NO COTIDIANO ESCOLAR}

Como se coloca, então, a questão da passividade inerente aos conceitos de indústria cultural e cultura de massa em sua relação com as singularidades cooperantes da multidão no cotidiano escolar? Imersa nas redes, a escola se apresenta como um locus de reprodução ou produção cultural alternativa?

O professor, assim como o aluno, ao chegar à escola, não abandona os mitos, as crenças, as ideias próprias de seu grupo social, nem conseguiria fazê-lo, pois carrega consigo processos de subjetivação e/ou formas de subjetividade de algum modo instituídos a partir de um sistema sociopolítico, econômico e cultural. 
Portanto, o imaginário social não se institui como objeto de conhecimento, de tal forma que possamos identificá-lo por procedimentos imediatos. Investigá-lo significa adentrar-se pelas vias da linguagem, dos ritos, dos mitos, admiti-lo como algo que institui, instituindo sentido à vida humana e social.

É, assim, necessário analisar a manipulação da imagem-representação (seu uso, consumo e produção) pelos usuários que não a fabricam. Só então é que se pode apreciar a diferença entre a produção primária e a secundária que se escondem nos processos de sua utilização.

$\mathrm{Na}$ medida em que os professores deixam de ser responsáveis pela produção dos objetivos, conteúdos, métodos de seu trabalho (transferidos para equipes técnicas, livros didáticos e outros), ocorre um estranhamento entre eles e sua produção/trabalho, com consequências evidentes para o uso por parte dos alunos. Nesse processo, tanto professores quanto alunos tendem a ser consumidores e/ou usuários de saberes e lógicas alienígenas para eles. Isso, porém, não ocorre de modo sempre passivo. Professores e alunos fazem das ações rituais, representações ou leis, que lhes são impostas, outras coisas que não aquelas que o doutrinador julgava obter. Os alunos e professores subvertem-nas, não as rejeitando diretamente, mas pela sua maneira de usá-las para fins e em função de referências estranhas ao sistema do qual não podem fugir. $\mathrm{O}$ mesmo pode-se dizer em relação aos professores e alunos e também à tecnoburocracia escolar. Supõe-se, assim, que os usuários, segundo Certeau (2001, p. 40),

[...] façam uma bricolagem com e na economia cultural dominante, usando inúmeras e infinitesimais metamorfoses da lei, segundo seus interesses próprios e suas próprias regras [...]. Dessa atividade de formigas é mister descobrir os procedimentos, as bases, os efeitos, as possibilidades.

Foucault (2004) substitui a análise dos aparelhos que exercem o poder pela dos "dispositivos", procedimentos técnicos minúsculos que, atuando sobre e com os detalhes, redistribuem os espaços para transformá-los no operador de uma vigilância generalizada. Se é verdade que, por toda a parte, se estende a rede da "vigilância", mais urgente ainda é descobrir como é que uma sociedade inteira não se reduz a ela: que procedimentos populares (também minúsculos e cotidianos) jogam com os mecanismos disciplinadores e não se conformam a eles.

A escola, de modo geral, como a sociedade, tende a funcionar numa sociedade de formigas. $\mathrm{Na}$ verdade, a chegada dessa sociedade de formigas começou com o enquadramento das massas às racionalidades niveladoras.

A escola moderna assumiu uma forma de organização que, entretanto, não é a única possível, mas, apenas, a que historicamente lhe foi dada, baseada em ritos, exercícios, invocação de autoridade, silêncio e imobilidade, relações impessoais, formais e burocráticas, produzindo a alienação do professor e do aluno, com relação aos fins do seu trabalho.

Sendo assim, se a ordem pode ser considerada a primeira obsessão das escolas, a segunda é manter os alunos ocupados, saltando à vista o paralelismo entre a posição do professor e do aluno e a do trabalhador assalariado: o trabalhador vende 
a sua força de trabalho; professores e alunos põem a sua capacidade à disposição da instituição em seu tempo e finalidades.

Ante o exposto, torna-se evidente que a escola parece se efetivar, ainda, intensamente, na dicotomia entre os lugares e os espaços e tempos da criação e da ação política.

Os trabalhos de professores e alunos, ao se inscreverem num "coletivo anônimo", não sendo conectados a uma rede de intercâmbios sociais, profissionais e textuais, não estabelecem nem o lugar, nem o espaço, nem o tempo dessa produção prático-discursiva.

De acordo com Certeau (2001, p. 201),

Um lugar é a ordem (seja qual for) segundo a qual se distribuem elementos nas relações de coexistência. Aí se acha, portanto, excluída a possibilidade de duas coisas ocuparem o mesmo lugar. Aí impera a lei do "próprio": os elementos considerados se acham uns ao lado dos outros, cada um situado num lugar próprio e distinto que o define.

E, mais adiante:

Existe espaço sempre que se tomam em conta vetores de direção, quantidades de velocidade e a variável tempo [...]. Espaço é o efeito produzido pelas operações que o orientam, o circunstanciam, o temporalizam e o levam a funcionar em unidades polivalentes de programas conflituais ou de proximidades contratuais. Em suma, o espaço é um lugar praticado. Assim a rua geometricamente definida por um urbanismo é transformada em espaço pelos pedestres. (idem, ibidem)

Os espaços, portanto, são ações de sujeitos praticantes. Uma escola geométrica e arquitetonicamente definida é transformada em espaço pelos professores, alunos e outros agentes por meio de suas práticas discursivas que transformam incessantemente lugares em espaços ou espaços em lugares. Os espaços exibem operações que permitem percursos, passagens, intercâmbios, trocas, compartilhamentos e não apenas a determinação da lei de um "lugar próprio", pois a lei de um "lugar próprio" se expressa pela autoria definida e, portanto, pela criação, mesmo que personalizada/individualizada.

$\mathrm{O}$ atomismo social que, durante séculos, serviu de postulado para uma análise da sociedade supõe como unidade elementar o indivíduo, a partir do qual seriam compostos os grupos. A escola que, aparentemente, funciona baseada na atomização do seu corpo social, estranhamente, consegue não levar em consideração o indivíduo, mas um corpo social anônimo, distinto da singularidade da multidão. Assim, professores são tratados e tratam alunos a partir não de sua individualidade e/ou características próprias ("lugar próprio"), mas a partir de um coletivo anônimo e/ ou da abstração de um aluno idealizado.

A extensão totalitária dos sistemas de produção (televisiva, comercial, escolar etc.) não deixa aos "consumidores" um espaço e um tempo em que possam marcar o que fazem com os produtos. A escola não deixa aos professores e alunos um espaço e 
um tempo de criação do seu trabalho. O resultado de seu trabalho é, para a maior parte dos professores e alunos, profundamente indiferente do ponto de vista do significado atribuído por eles ao conhecimento e/ou à ação praticada. Interessa, sobremaneira, aos alunos a mensuração quantitativa expressa em notas, conceitos e/ou o resultado na aprovação ou reprovação; e, aos professores, o credenciamento de seu trabalho expresso em títulos ou equivalentes que outorguem uma legitimidade abstrata às suas ações.

Tem-se, porém, que considerar que esse processo é resultante de uma rede intrincada de relações (redes de sociabilidade). A análise mostra que a relação (sempre social) determina seus termos, e não o inverso, e que cada individualidade é o lugar onde atua uma pluralidade incoerente (e muitas vezes contraditória) de suas determinações relacionais. Nessas determinações relacionais se incluem as combinatórias de operações entre consumidores e usuários, fundadas no status da relação reprodução-dominação e/ou no estatuto de sujeitos (individuais ou coletivos) dominados, mas não necessariamente passivos ou dóceis. Por exemplo, assim como as imagens difundidas pela televisão e o tempo gasto junto ao televisor só adquirem concretude se completados pelo estudo daquilo que o consumidor cultural "fabrica" durante essas horas e com essas imagens, do mesmo modo as ações dos professores aos quais alunos estão submetidos durante horas, diariamente, pressupõem o exame dos seus efeitos sobre os alunos como "consumidores ou usuários", tais como: passividade, interesse/desinteresse, violência, evasão, aprendizagem etc. Tem-se ainda que considerar que a pluralidade, aparentemente incoerente das relações, aponta a necessidade de o trabalho educativo considerar a singularidade pessoal/grupal como uma unidade na multiplicidade, pois, como foi visto, a instauração dos espaços e dos tempos escolares se faz tomando-se por base o lugar singular que deve abrir-se para a produção de redes relacionais.

Certeau (idem, p. 61) diverge da perspectiva de "homem ordinário" delineada por Freud, para quem apenas um pequeno número de pensadores e artistas seria capaz de metamorfosear o trabalho em prazer pela sublimação, enquanto: "[...] o homem ordinário, conjuga o seu discurso com a multidão cujo destino comum consiste em ser ludibriada, frustrada, forçada a trabalho cansativo, submetida à lei e ao tormento da morte".

Para Certeau (idem), o enfoque da cultura começa quando o "homem ordinário" se torna o narrador (voz), quando redefine o lugar (comum) das práticas discursivas e o espaço (partilhado) de seu desenvolvimento. Dessa forma, o espaço e o tempo de criação individualizada deve remeter aos espaços e tempos de criação coletiva e experimentação política.

Assim, nesse escopo de análise, os espaços e os tempos de criação coletiva e a ação política aparecem como componentes fundamentais no processo de transformação da escola. Importa, nesse sentido, a análise das significações instituídas, pois é possível trabalhar as resistências, incentivar as forças criadoras do grupo, os processos de valorização da diferença e do coletivo escolar, quando se conhecem os mitos, os símbolos, os ideários que lhe servem de suporte.

A criação é a posição de novas determinações, a capacidade de fazer surgir o que não estava dado e guarda o princípio da reflexibilidade, da problematização, da 
experimentação e da deliberação, sendo, portanto, diferente da atividade puramente reflexa. Remete ao conceito de redes de sociabilidade, de coletivo, e à relação entre saberes, fazeres, afetos e poderes.

As estruturas tecnocráticas das escolas são alteradas por "maneiras de fazer" e/ou por uma multiplicidade de "táticas" articuladas entre os detalhes do cotidiano: formas sub-reptícias que são assumidas por alunos e professores pela criatividade dispersa, tática e bricoleuse dos grupos ou dos indivíduos.

Existe, entretanto, uma lógica nessas operações multiformes e fragmentárias. Elas obedecem a regras, a formalidades que devem e podem ser captadas pela análise de, entre outras coisas: práticas de leitura, práticas de espaços, formas e utilização de ritualizações cotidianas, reempregos e funcionamento da memória nas práticas cotidianas etc. Assim, professores e alunos devem buscar "indícios" de práticas alternativas que permitam escapar a uma marginalidade que não é de um pequeno grupo, mas uma marginalidade de massa, ou seja, dos professores e alunos das escolas, buscando desvendar a atividade cultural dos "não produtores de cultura", uma atividade não assinada, heterogênea e bricoleuse.

A cultura articula conflitos e, volta e meia, legitima, desloca ou controla a razão do mais forte. Ela se desenvolve no elemento de tensões e, muitas vezes, de violências, a quem fornece equilíbrios simbólicos e compromissos temporários. Como afirma Certeau (idem, p. 45), "As táticas do consumo, engenhosidade do fraco para tirar partido do forte, vão desembocar então em uma politização das práticas cotidianas".

Professores criam artimanhas e táticas para controlar a razão do mais forte, assim como os alunos o fazem em relação aos professores e a outras autoridades escolares. Importa que essas táticas se expressem, politicamente, pela ação projetada, e não de forma difusa e/ou cega (nó cego sem linha de fuga da rede de interações).

Segundo José Machado Pais (2006), há duas maneiras de olharmos as culturas: a) por meio dos processos que as prescrevem; e b) pelas expressividades e/ou performances cotidianas. No primeiro caso, pela relação com as formas prescritivas que as circunscrevem; no segundo, pela abertura da expressividade.

Nesse sentido, o autor aborda os conceitos desenvolvidos por Gilles Deleuze e Félix Guattari (1997) de espaço liso e espaço estriado, aos quais, e para a análise que propomos, associamos as noções de tática e estratégia de Certeau (2001).

Para Deleuze e Guattari, o espaço estriado é revelador da ordem e do controle, e os seus trajetos estão confinados às características do espaço que os determina. Em contraposição, o espaço liso abre-se ao caos, ao nomadismo, ao devir, ao performativo, ou seja, como um espaço de um patchwork (colcha de retalhos, de misturas) e, portanto, de abertura para novas sensibilidades e realidades.

As formas-forças performativas abrem-se ao experimentalismo e/ou às novas experimentações por meio de três vetores principais: o lúdico, a ênfase visual, o excesso. Nesse sentido, o espaço liso seria um espaço nômade, sem trajetos previamente determinados.

Desse modo, ao espaço liso corresponderia um espaço no qual se desenvolve a "resistência"; e ao espaço estriado, um espaço sedentário, instituído pelo "aparelho 
de Estado" como máquina abstrata de poder hegemônico e sobrecodificante que segundo Deleuze e Guattari (1996, p. 78) - “[...] se exerce sobre segmentos que ele mantém ou deixa subsistir, mas possui sua própria segmentaridade e a impõe".

Importa considerar que, para Deleuze e Guattari, os dois espaços só existem coexistindo. Ou seja, graças às misturas entre si, “[...] o espaço liso não para de ser traduzido, transvertido num espaço estriado; o espaço estriado é constantemente revertido, devolvido a um espaço liso" (Deleuze; Guattari, 1997, p. 180).

Esses conceitos de espaço liso e estriado guardam aproximação com os conceitos de tática e estratégia desenvolvidos por Certeau (2001), que trabalha explorando a problemática de usos, modos de fazer dos usuários, insistindo em sua capacidade de desviar, de contornar a racionalidade dos dispositivos estabelecidos pela ordem estatal e comercial.

Para Certeau, as evidências são contingentes e, sendo assim, o que é evidente não é senão o resultado de uma disposição do espaço, de uma particular (ex)posição das coisas e de uma determinada constituição do lugar do olhar. E isso porque não vemos tudo o que o constrange no próprio movimento que o torna possível. Nosso olhar está constituído por todos esses aparatos que nos fazem ver, e ver de uma determinada maneira, ver e crer.

Entretanto, Certeau quer nos ensinar que o nosso olhar é também mais livre do que pensamos, porque o que o determina não é tão necessário nem tão universal quanto acreditamos. O que determina o olhar tem uma origem, depende de certas condições históricas, socioculturais e práticas e, portanto, como todo o contingente, está submetido à mudança e à transformação, dando margem a que seja possível ver de outro modo.

Certeau (idem) apresenta a noção de tática não em oposição à noção de estratégia, mas como uma série de procedimentos que, constantemente, utiliza para subverter as referências de um lugar próprio como um espaço que é controlado por um conjunto de operações (estratégias) fundadas sobre um desejo e sobre um conjunto desnivelado de relações de poder.

Para ele, estratégias e táticas devem ser lidas como partes de um único processo: a tentativa de uma sociedade se organizar. Dessa forma, a distinção entre táticas e estratégia tem um caráter enunciativo e um caráter operacional que busca compreender as relações de poder e, nesse caráter enunciativo, inscreve-se a não aceitação de uma linguagem privilegiada: científica, cotidiana ou popular. Se as estratégias têm por objetivo a organização de um espaço controlado, as táticas dirigem-se para a possibilidade de operações e enunciações que não supõem um controle ou uma regra universal e, evocando um movimento contínuo, porém indeterminado, abrem fissuras no poder estabelecido.

Tais fissuras se apresentam como resistência ao estabelecido e, como escreveu Certeau, longe de se constituírem uma revolta ou uma revolução, apresentam-se como subversão comum e silenciosa, mas não deixam de ser resistência .

Assim, as táticas (espaço de reconhecimento da criatividade cotidiana) não pretendem constituir uma teoria revolucionária, visto sua indeterminação e contingência. Porém, se o ato estratégico organiza o espaço próprio (lugar), o momento tático tem a mesma ambição. Um como o outro, um pressupondo o outro, ambos visam à organização espacial. O primeiro de forma determinada; e o segundo, em sua indeterminação (espaço liso) e/ou recusa de operar com regras modelares ou modelizantes (espaço estriado). 
Desse modo, a fuga de uma gestão funcionalista dos espaços e tempos escolares implica uma configuração em que os "grandes relatos" não esmaguem os "pequenos relatos" (idem), como numa concepção de dinâmica social que busque compreender como os "acontecimentos" se articulam na dinâmica entre espaços lisos e estriados, visto que, se lugares e espaços devem ser pensados juntos, estratégias e táticas também.

A questão que atravessa esta análise, portanto, vem a ser: como trabalhar os espaços e os tempos escolares como espaços nômades, como espaços de inventividade e incremento de expressividade, como característica das experiências dos professores e dos alunos mediados por artefatos escolares que circulam no cotidiano escolar? Como imersa nas redes e com as redes, pode a escola potencializar a emergência da singularidade da multidão no trato dos produtos culturais que a atravessam e são por ela atravessados?

\section{A CULTURA E AS REDES DE SOCIABILIDADE NA PRODUÇÃO DO CURRÍCULO}

Ao abordar a questão do currículo no cotidiano escolar, procuramos enfocar a dimensão relativa a como potencializar a constituição de redes de sociabilidade singulares e de cooperação para a produção curricular.

Nesse sentido, gostaríamos de apontar a potência da concepção de currículo como rede de conversações e ações que criam novas formas de comunidade, o que implica assumir a ideia de "potência de ação coletiva". Nesse sentido, tomamos como hipótese principal que essa "potência" depende fundamentalmente da capacidade de indivíduos e de grupos se colocarem em relação para produzirem e trocarem conhecimentos, gerando, então, o agenciamento de formas-forças comunitárias, buscando melhorar os processos de compartilhamento e aprendizagem nas coletividades locais, bem como no interior de redes cooperativas de todo tipo. Ou seja, debater os "possíveis" do currículo vivido a partir dos conhecimentos, linguagens, afetos e afeç̧ões que estão em circulação nas práticas discursivas, em redes de conversações e ações complexas no cotidiano escolar (Carvalho, 2009).

Desse modo, ao focarmos as práticas discursivas no cotidiano escolar, entendemos que elas estão inseridas em todo um esforço coletivo, envolvendo a participação de múltiplos agentes sociais que, direta ou indiretamente, contribuem para a melhoria das condições de vida de pessoas e populações. Compreendemos também que a dimensão política se efetiva pelos fluxos de conhecimentos, linguagens e afetos, enfim, em redes de trabalho informativo, linguístico e afetivo que ocorrem na busca da emergência de outra concepção de público, de coletivo e de currículo.

Mesmo focando nosso trabalho no currículo vivido, ressaltamos que o cotidiano escolar deve ser visualizado como um elemento integrado a todas as redes mais amplas de trabalho social que se enredam com os processos de produção de subjetividades na sociedade capitalista.

Nesse sentido, reconhecemos e defendemos a natureza eminentemente micropolítica e conversacional do trabalho em educação na constituição desse cotidiano escolar, em seus efeitos sobre a produção do currículo como redes de conversações e ações complexas. 
Portanto, consideramos que o currículo escolar, como rede de conversações e ações complexas, busca os possíveis da sua constituição, fundado nas dimensões da conversação e da ação para a recriação de saberes, fazeres e afetos da/na/com a escola, constituindo redes de "inteligência coletiva".

A noção de "inteligência coletiva" refere-se à ideia de "potência de ação coletiva" dos grupos, tomando-se, como hipótese principal, que essa "potência" depende fundamentalmente da capacidade de indivíduos e grupos interagirem, pondo-se em relação, e, dessa forma, produzirem, trocarem e utilizarem conhecimentos, linguagens e afetos/afecções por meio de conversações e ações organizadas a partir da formação de aparatos cooperativos de produção e de solidariedade (Hardt; Negri, 2005).

Partimos, desse modo, do pressuposto de que a constituição de currículos compartilhados pode estar na origem de uma nova racionalidade, assim como do desejo de que essa constituição possa avançar à medida que, pela linguagem, pelo conhecimento, pelos afetos e afecções, se introduzam experimentações e exercícios de solidariedade cada vez mais vastos.

Cumpre considerar que, num currículo como processo de conversação e ação complexa, o conhecimento acadêmico, a subjetividade e a sociedade estão inextricavelmente unidos. É essa ligação, essa promessa de educação para as nossas vidas privadas e públicas, que a teoria do currículo deve elaborar, persistindo na causa da educação pública, como propriedade comum, para que um dia as escolas possam trabalhar a diferença e afastar a exclusão e a desconexão. Quando assim fizermos, as escolas não serão mais fábricas de competência e de conhecimento, nem negócios acadêmicos, mas escolas: locais de educação para a criatividade, a erudição, a intelectualidade interdisciplinar, os saberes transversais, a comunicação, a afetividade cooperativa; a forma de afetar e ser afetado na produção de cooperação para o trabalho coletivo.

É nesse desejo social da coletividade definida como um corpo político que se inscreve a perspectiva do currículo como conversação e ação complexa conectada com uma produção de subjetividade inventiva/criativa.

Esse corpo político se manifestaria em uma ação problematizada pela conversação, meio potencial agenciador de outras práticas. As conversações, nesse sentido, remetem a novos questionamentos das situações vividas e, dentro das situações, potencializam, pela criação e experimentação, a possibilidade do singular.

No cotidiano escolar, professores e alunos, como quaisquer dos cidadãos de uma comunidade, estão inseridos em uma formação sociocultural que eles engendram, mas são, também, por ela engendrados. Sendo assim, a perspectiva é processual, visto não ser possível o estabelecimento de nenhum consenso sobre o que venha a ser o "currículo ideal". Na relação é que a dimensão política do pedagógico será estabelecida. Essa relação se processará não apenas entre conhecimentos, linguagens, afetos e afecções e entes educativos inseridos no cotidiano escolar, pois atravessará outros entes e instâncias com os quais o currículo vivido estabelecerá conexões e ações.

No âmbito do currículo escolar, propomos uma formação orientada a fazer com que professores possam conversar-conversar, alunos e professores possam conversar-conversar, escolas e outras instâncias, dentre as quais as mídias e outros produtos culturais, possam conversar-conversar, considerando a alteridade, de modo a possibilitar a conversação dos outros consigo mesmos. Assim, para além de conhecer "textualmente"o 
outro, independentemente do saber científico acerca do outro, é preciso poder vincular/ compartilhar experiências de uns com as experiências dos outros, visando a estabelecer encontros que potencializem os saberes, fazeres e afetos, constituindo um movimento da comunidade educativa que outorgue alternativas possíveis e sensíveis.

\section{CONCLUSÃO}

Recorremos mais uma vez a Certeau (1995, p. 9): "Para que haja verdadeiramente cultura, não basta ser autor de práticas sociais; é preciso que essas práticas sociais tenham significado para aquele que as realiza”. E acrescenta: "[...] a cultura não consiste em receber, mas em realizar o ato pelo qual cada um marca aquilo que os outros lhe dão".

Sabemos que a cultura está cada vez mais nas mãos do poder. Entretanto, aprendemos, com esse mesmo autor, que a cultura no singular é mortífera e ameaça a criação e a invenção. Por isso, defendemos que seja desvelada toda a riqueza da pluralidade das culturas presentes nos currículos praticados por professores e alunos no cotidiano escolar. Ou seja: que deixem emergir os diversos sistemas de referências e significados que estão silenciados e mortificados na escola.

Acrescenta ele, ainda, que, quanto mais a economia se unifica, mais a cultura deve diversificar-se, pois ela é uma prática significativa que não consiste em receber pronto, mas em fabricar tudo o que nos é oferecido para viver, pensar e sonhar. Toda cultura requer, portanto, uma ação, um modo de apropriação, uma conversação. Janete Carvalho $(2004$, p. 1) lembra que "[...] o currículo praticado envolve as relações de poder, cultura e escolarização, representando, mesmo de forma nem sempre explícita, o jogo de interações e/ou as relações presentes no cotidiano escolar".

Portanto, em caminhos sem fim, na medida em que os professores e alunos deixam de ser responsáveis pela produção de seu trabalho e se situam como massa e não como multidão singular nas redes de saberes, fazeres e afetos que constituem, eles tendem a ser consumidores e/ou usuários de saberes e lógicas alienígenas. $\mathrm{Na}$ medida em que, nas redes e com as redes, se expressa como singularidade cooperante, o corpo educativo passa a concretizar-se como um corpo político.

Enfim, em caminhos sem fim, propomos currículos como redes de conversações e ações complexas que, envolvendo uma "nova" racionalidade, se voltem para a potência das práticas pedagógicas como ações curriculares coletivas, grávidas de solidariedade e encharcadas de vida, acenando para alternativas "outras".

Concluímos nossa argumentação, tomando como base observações registradas em pesquisa de campo, realizada por Janete Carvalho e Sandra Silva (2009), que apontam que alguns "usos" do lúdico, algumas problematizações e experimentações realizadas confirmam que professores e alunos atuam explorando outros modos de realização dos espaços e tempos praticados no cotidiano escolar. Escapam, assim, aos espaços e tempos somente determinados por formas prescritivas no uso dos produtos culturais. Pontuamos, por consequente, como hipótese substantiva para novas investigações, que tais problematizações e experimentações são potencializadas pelo incremento de constituição de redes de sociabilidade e cooperação entre diferentes instâncias e contextos educativos, nas quais a cultura se expressa, sempre, "no plural". 


\section{REFERÊNCIAS}

Canclini, Néstor García. Diferentes, desiguais e desconectados: mapas da interculturalidade. 2. ed. Rio de Janeiro: Ed. UFRJ, 2007.

Carvalho, Janete Magalhães. Diferentes perspectivas da profissão docente na atualidade. 2. ed. Vitória: Edufes, 2004.

O cotidiano escolar como comunidade de afetos. Petrópolis: DP et Alii., 2009.

; Silva, Sandra Kretli. O uso dos artefatos culturais como movimentos táticos e estratégicos, em espaços lisos e estriados, nos currículos praticados no cotidiano escolar. Revista Teias, Rio de Janeiro: Proped/UERJ, v. 10, n. 20, set./dez. 2009.14 p.

Certeau, Michel de. A cultura no plural. Campinas: Papirus, 1995.

. A invenção do cotidiano, 1: artes de fazer. 6. ed. Petrópolis: Vozes, 2001.

Deleuze, Gilles; Guattari, Félix. Micropolítica e segmentaridade. In: Mil platôs: capitalismo e esquizofrenia. São Paulo: Ed.34, 1996.v. 3, p. 83-115.

. O liso e o estriado. In: . Mil platôs: capitalismo e esquizofrenia. São Paulo: Ed. 34, 1997.v. 5, p. 179-214.

Duarte, Fábio; Quandt, Carlos; Souza, Queila. O tempo das redes. São Paulo: Perspectiva, 2008. Foucault, Michel. Vigiar e punir. 29. ed. Petrópolis: Vozes, 2004.

Ética, sexualidade, política. Organização de Manoel de Barros Motta. 2. ed. Rio de Janeiro: Forense Universitária, 2006. (Coleção Ditos \& Escritos, v. 5).

Hardt, Michael; Negri, Antonio. Multidão. 8. ed. Rio de Janeiro: Record, 2005.

Negri, Antonio. Cinco lições sobre Império. Rio de Janeiro: DP\&A, 2003.

A constituição do comum. Conferência Inaugural do II Seminário Internacional

Capitalismo Cognitivo: Economia do Conhecimento e a Constituição do Comum. Rio de Janeiro: RITS, 2005.

PAIs, José Machado. Buscas de si: expressividade e identidades juvenis. In: AlmeIdA, Maria Isabel Mendes de (Org.). Culturas jovens: novos mapas do afeto. Rio de Janeiro: Jorge Zahar, 2006.p. 7-21.

Yúdice, George. A conveniência da cultura: usos da cultura na era global. Belo Horizonte: Editora UFMG, 2004.

Williams, Raymond. Cultura. 2. ed. Rio de Janeiro: Paz e Terra, 2000.

Zuin, Antonio Álvaro Soares. Sobre a atualidade do conceito de indústria cultural. Cadernos CEDES, Campinas: CEDES/UNICAMP, v. 21, n. 54, p. 9-18, maio/ago. 2001.

\section{SOBRE A AUTORA}

Janete Magalhães Carvalho é doutora em educação pela Universidade Federal do Rio de Janeiro (UFRJ). Professora da Universidade Federal do Espírito Santo (UFES). E-mail: janetemc@terra.com.br 


\section{JANETE MAGALHÃES CARVALHO}

\section{Produção cultural e redes de sociabilidade no currículo e no cotidiano escolar}

Toma cultura(s) como a pluralidade de processos sociais de produção e "usos" das significações da vida social. Problematiza os conceitos de indústria cultural, cultura de massa e "multidão", apontando para a urgência de movimentos singulares e cooperativos em direção ao comum, construído por lutas e trabalho: material e imaterial. Analisa o atravessamento das redes de sociabilidade na produção do cotidiano escolar, enfocando os usos e consumos da produção cultural. Destaca como a escola parece se efetivar, ainda, intensamente, na dicotomia entre os lugares e os espaços e os tempos da criação e da ação política. Considera, assim, a necessidade da utilização dos espaços e tempos escolares lisos e estriados de modo tático e estratégico, para o incremento das redes de "inteligência coletiva", visando à constituição do currículo em redes de subjetividades político-inventivas, de sociabilidades múltiplas, nas quais a cultura é expressa, sempre, no plural.

Palavras-chave: cultura; produção cultural; redes de sociabilidade; currículo; cotidiano escolar.

\section{Cultural production and networks of sociability in the curriculum and in the daily school life}

The paper sees culture as the plurality of social processes of production and "uses" of the meanings of social life. It problematizes the concepts of cultural industry, mass culture and "crowd", pointing to the urgency of singular and cooperative movements toward the common, built by struggles and work: material and immaterial. The research analyzes the crossing of 
the networks of sociability in the production of the school daily life, focusing on the uses and consumptions of cultural production. It highlights how the school still seems to operate intensely in the dichotomy between the places and spaces and the times of creation and political action. Thus, it considers the need to use school spaces and times that are smooth and striated in a tactic and strategic way, to increment networks of "collective intelligence", aiming at constituting the curriculum in networks of political and inventive subjectivities, of multiple sociability, in which culture is always expressed in the plural.

Keywords: culture; cultural production; sociability networks; curriculum; daily school life.

\section{Producción cultural y redes de sociabilidad en el currículo y en el cotidiano escolar}

Considera cultura(s) como la pluralidad de procesos sociales de producción de "usos" de las significaciones de la vida social. Problematiza los conceptos de industria cultural, cultura de masa y "multitud", señalando la urgencia de los movimientos singulares y cooperativos direccionados a lo común, construido por luchas y trabajo: material e inmaterial. Analiza el cruce de las redes de sociabilidad en la producción del cotidiano escolar, focalizando los usos y consumos de la producción cultural. Destaca como la escuela parece efectivarse, todavía, intensamente, en la dicotomía entre los lugares, espacios y tiempos de la creación y de la acción política. Considera, asi, la necesidad de utilización de los espacios y tiempos escolares lisos y estriados de forma táctica y estratégica, para el incremento de las redes de "inteligencia colectiva", visando la constitución del curriculo en redes de subjetividades político-inventivas, de sociabilidades múltiples, en las que la cultura se manifiesta, siempre, en el plural.

Palabras clave:cultura; producción cultural; redes de sociabilidad; currículo; cotidiano escolar. 